This is an Open Access article, distributed under the terms of the Creative Commons

Attribution licence (http://creativecommons.org/licenses/by/4.o/), which permits unrestricted re-use, distribution, and reproduction in any medium, provided the original work is properly cited.

doi:10.1017/So144686X16000143

\title{
Ethnic elders and pension protection in the United Kingdom
}

\author{
ATHINA VLACHANTONI*†, ZHIXIN FENG*, \\ MARIA EVANDROU $* \dagger$ and JANE FALKINGHAM $\dagger$
}

\begin{abstract}
Pension receipt in later life is determined by the way in which individuals' pension contributions and circumstances over the lifecourse interact with eligibility rules. Within the British context, such pensions relate to sources such as the State Pension, an occupational or private pension, and Pension Credit. Existing research shows that membership of certain ethnic groups is associated with a lower likelihood of receiving occupational or private pensions. Data from Understanding Society allows us to build on existing evidence by examining the factors associated with the receipt of three different kinds of pension income-State, occupational/private and Pension Credit-among older men and women from separate Black and Minority Ethnic (BME) groups. The results show that belonging to certain BME groups reduces one's chances of receiving the State Pension or an occupational/private pension, but increases the chance of receiving Pension Credit. The gender-specific analysis shows that these results hold true for many BME groups of men, whereas among women, only Pakistani women are less likely than White British women to receive an occupational/private pension. Such findings provide up-to-date empirical evidence that ethnic inequalities in pension protection are still evident and contribute to the increasingly important debate in the United Kingdom and elsewhere regarding migrants' social security and welfare over the lifecourse and in later life.
\end{abstract}

KEY WORDS - pensions, elderly, ethnicity, Understanding Society.

\section{Introduction}

Existing research has described individuals from Black and Minority Ethnic (BME) origin as one of the groups comprising 'the under-pensioned' in

* Centre for Research on Ageing, Faculty of Social, Human and Mathematical Sciences, University of Southampton, UK.

$\dagger$ ESRC Centre for Population Change, Faculty of Social and Human Sciences, University of Southampton, UK. 
society, along with individuals with impairments (Steventon and Sanchez 2008). Notwithstanding the considerable diversity within the BME population and between different ethnic groups, evidence shows that individuals from BME groups are less likely to be in paid employment during their working age and in later life, they tend to have lower earnings when in work, are less likely to qualify for State Pensions and are less likely to be saving for a private pension (Allmark et al. 2010). Such evidence has tended to focus on the analysis of employment patterns among current working-age individuals and the implications of such patterns for their eligibility for future receipt of the State Pension (Gough and Adami 2013; Vlachantoni et al. 2015). Focusing on the pensioner population, government evidence on the composition of pension income among individuals from ethnic minorities who are above the State Pension age has shown that elders from particular ethnic groups receive less income from a State Pension on average and more income from income-related benefits than their White British counterparts (Department for Work and Pensions 2015).

Understanding the differentials in pension protection between older individuals of ethnic origin is important as the British population is becoming increasingly diverse, and the BME population is ageing along with the rest of the population. According to the 2011 Census, individuals from BME communities comprised about 14 per cent of the total population in England and Wales (Office for National Statistics 2012), with individuals of Indian, Pakistani and Black Caribbean heritage constituting amongst the largest groups (Office for National Statistics 2005). Individuals from BME communities currently make up only around 8 per cent of the population aged $6_{5}$ and over in England and Wales (Office for National Statistics $2011)$; nevertheless projections show that by $205^{1}$, there will be an estimated 3.8 million people from BME groups aged $6_{5}$ and over, and 2.8 million aged 70 and over (Lievesley 2010). Against this background, this paper contributes to a better understanding of pension protection among older individuals from BME groups by examining the following research question: What is the association between older individuals' ethnicity and their receipt of income from a State Pension, an occupational/private pension and Pension Credit?

\section{Pension protection in the United Kingdom (UK)}

Pension income can be received from a number of different sources, including the state, the private market, the labour market and the family (Price 2008). The British pension system has historically relied on a relatively low-value State Pension, which is contributory, flat-rate and worth 
approximately 18 per cent of the national average earnings, and a relatively small public earnings-related scheme, topped up by means-tested benefits for those on low incomes and by private pensions for those with middle and high incomes (Pensions Policy Institute 2013). As a result, occupational/private pensions have been considered critical in securing financial adequacy for older people (Bardasi and Jenkins 2010). The means-tested benefit in the form of Pension Credit has 'topped-up' the incomes of poorer pensioners, but has also been associated with persistent non-takeup by approximately one-third of eligible recipients (Department for Work and Pensions 2012). The eligibility criteria for receiving each of these pension incomes are different; the discussion here refers to criteria in place at the time when the analysed data were collected. The State Pension is a flat-rate amount received by individuals who, in this analysis, had made at least 39 years' worth of contributions (this was changed to 30 years of contributions and more recently to 35 years starting from 2016); Pension Credit is a means-tested benefit which is composed of a Guarantee and a Savings element, and which takes into account one's income from pensions, benefits, earnings and other sources; and finally occupational/private pension income is received by individuals who have paid into an employer's pension scheme or a private pension account during their working life.

In order to capture the relative importance of different sources of pension income for older people from BME groups, three types of pension income are examined in the analysis: the State Pension, occupational/private pensions and Pension Credit. The distinction between the three types of pension income is critical when studying ethnic differences, as existing research has exposed a gap in the percentage of individuals qualifying for a State Pension or saving through a private pension between BME groups and the majority White population (Steventon and Sanchez 2008).

\section{Conceptualising the concept of ethnicity}

Examining the relationship between ethnicity and pension protection in later life requires an understanding of how both concepts have been operationalised in existing empirical analyses. In many nationally representative surveys, including the one used for the analysis in this paper, ethnicity is selfdefined by respondents. However, both the definition of the concepts of ethnicity and ethnic group, and the categorisation of responses are contested and dynamic areas, reflected in changes in the phrasing of questions, the available responses and the final categorisation of responses by researchers across time. For example, an ethnic group might refer to a group sharing common characteristics, such as religious affiliation, language and cultural 
norms, while at the same time, such characteristics may be used to distinguish a specific group from others, thereby denoting difference (Wimmer 2008). Similarly, ethnicity might be related to, but not be defined exactly as, other concepts such as one's race, nationality, migration history and heritage. Burton, Nandi and Platt (2008) emphasise the difference between conceptualising ethnicity as one part of an individual's identity-an approach favoured by psychologists; and perceiving ethnicity as contributing to social stratification through attaching particular outcomes to groups with particular characteristics - an approach which tends to be used by other researchers and by policy makers. The same authors point at the apparent contrast between the subjective measurement of ethnicity through selfdefined questions, and the aim to obtain a reliable or 'objective' definition of individuals' ethnicity (Burton, Nandi and Platt 2008). In this paper, we consider ethnicity to be one of the self-defined demographic and socio-economic characteristics which contribute to an individual's or group of individuals' identity, and which can help explain particular outcomes for such individuals or groups - in this case relating to pension protection in later life.

The use of pre-designed categories in the self-defined question on ethnicity, and its implications for the measurement of ethnicity over time, has also been studied to a significant extent, especially since 1991, when the question on ethnicity was first included in the UK Census. Both the wording of the question and the available response categories have changed between the 1991, 2001 and 2011 Censuses, making comparable research more challenging, on the one hand, albeit with the aim of providing more meaningful questions for the UK's increasingly diverse population (Jivraj 2012). For example, the 1991 Census question on ethnicity enquired 'which ethnic group [individuals] descend from', while the 2001 Census asked after 'individuals' ethnic group in terms of cultural background' and, finally, the 2011 Census asked individuals to simply define their 'ethnic group or background'. In spite of such changes, and challenges associated with them (e.g. self-definition of children in inter-racial unions), the evidence on the UK's increasing ethnic diversity is undisputable (Office for National Statistics 2012). The proportion of the UK's non-White population, which in broader terms could be taken to refer to ethnic minorities, increased from 7 per cent in 1991, to 9 per cent in 2001 and 14 per cent in 2011 (Jivraj 2012). Challenges associated with the changing nature of ethnicity questions are not dealt with in this paper, which presents crosssectional analysis of ethnic minority groups. For the purposes of this paper, individuals are simply asked 'what is your ethnic group?', and provided with 18 possible responses (including 'other' which is further analysed), which are then grouped into eight categories. 


\section{Pension protection among minority ethnic groups in Britain}

Empirical evidence comparing pension protection among older individuals from different ethnic groups shows significant differentials not only between the White majority and the ethnic population as a whole, but also between different ethnic groups and the different genders. According to the 2013/14 Pensioner Income Series, the mean gross income of pensioner units between 2010 and 2014 was $£_{492}$ per week for White British individuals, $£_{423}$ per week for Asian/Asian British/ Chinese individuals and $£_{35^{\circ}}$ per week for Black/African/Caribbean/ Black British individuals (Department for Work and Pensions 2015: table 5.4). Examining the composition of this income reveals further gaps, with 98 per cent of White British pensioners receiving a State Pension compared to 84 per cent of the Asian and 88 per cent of Black elders, and conversely 27 per cent of White British receiving income-related benefits compared to 44 per cent of Asian and 45 per cent of Black minority elders. In addition, less than one-third of Asian elders (30\%) and 47 per cent of Black elders received income from an occupational pension compared to 63 per cent of White British pensioner units (Department for Work and Pensions 2015: table 5.4). This contributes to 47 per cent of Indian pensioners being in the bottom two quintiles of the income distribution for the pensioners' population, compared to 45 per cent of Black/African/ Caribbean/Black British pensioners and $3^{6}$ per cent of the majority White population (Office for National Statistics and Department for Work and Pensions 2015). Earlier analysis of the Family Resources Survey between 1994 and 2008 indicated that individuals up to the age of $6_{5}$ from Pakistani, Bangladeshi and Black heritage consistently report having the lowest incomes as well as the lowest savings for retirement (Gough and Adami 2013). In addition, Pakistani and Bangladeshi pensioners have been shown in both quantitative and qualitative research to be more likely to rely on means-tested benefits than pensioners from other BME groups (Berthoud 1998; Burton 1996; Gough and Hick 2009).

Such differentials may be the result of a complex set of reasons, including the timing of arrival and commencing social insurance contributions in the UK, employment patterns, relatively low-paid earnings across the lifecourse when in work, as well as cultural reasons. Low income over the lifecourse can be directly affected by low participation rates in the labour market for particular ethnic groups, and research has consistently revealed a disadvantage amongst Pakistani and Bangladeshi communities in this respect (Ginn and Arber 2001). Between July and September 2013, 78 per cent of White men aged 16 and over were in the labour market, compared to 62 per cent 
of Pakistani and 64 per cent of Black/African/Caribbean men of the same age, while the equivalent rates for women were 69 per cent among the White group, 31 per cent among Pakistani women, $5^{8}$ per cent among Black/African/Caribbean women and 34 per cent among Bangladeshi women (Office for National Statistics 2013). Other research has shown that Pakistani and Bangladeshi pensioners are less likely than White pensioners to contribute to, and be aware of, an employer's pension scheme (Nesbitt and Neary 2001). Finally, gender can further contribute to the 'ethnic pension penalty', with Bangladeshi and Pakistani women being the least likely among all men and women from BME groups to be benefiting from a private pension scheme (Ginn and Arber 2001; Gough and Adami 2013).

The policy significance of examining differentials in terms of pension protection also relates to the fact that particular ethnic communities experience further dimensions of disadvantage which can affect wellbeing in later life. Research has consistently shown that Pakistani, Bangladeshi and Indian individuals aged $5^{\circ}$ and over are more likely to report a limiting long-standing illness, which can affect their capacity to engage in paid work and contribute to their pension entitlement (Evandrou 2000 $a$ ). At the same time, women from these three ethnic communities are more likely to provide

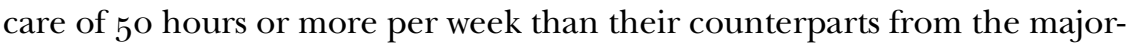
ity White population or other ethnic groups (Office for National Statistics 2005), which can have an adverse effect on their labour market participation. Other factors associated with one's living arrangements may also contribute to such differentials. For instance, older persons from BME groups are more likely to live in large households, which may be advantageous in terms of family support and the pooling of resources within the household, but on the other hand, may have an adverse impact in terms of overcrowded accommodation and the inadequacy of pooled resources (Pensions Policy Institute 2013).

\section{Data and methodology}

The research employs Wave 1 data (collected between January 2009 and March 2011) from Understanding Society, which is a longitudinal survey of the members of approximately 4 o,ooo households in the UK. The sample of Understanding Society used here includes the General Population (GP) and an Ethnic Minority Boost sample (EMB). The addresses of the sample were randomly selected from the Postcode Address File in Great Britain and the Land and Property Services Agency list of domestic properties in Northern Ireland. In each household, all 
individuals aged ten years and over were eligible for interview. Computer Aided Personal Interview was used to administer the household and individual adult questionnaires. The response rates for the GP and EMB were 82 and 73 per cent, respectively (Boreham, Boldysevaite and Killpack 2012). Although Wave 1 is the not the most recent wave in this survey, significant attrition in the ethnic groups between Waves 1 and 3 render Wave 1 the most appropriate for yielding adequately large cell counts for older individuals from ethnic groups. The data-set is ideal for this study, as it includes an EMB sample, designed to include at least 1 , ooo individuals from five ethnic groups: Indian, Pakistani, Bangladeshi, Caribbean and African. The analytical sample for this paper includes all adults aged from the State Pension Age and over (6o for women, $6_{5}$ for men at the time of data collection), totalling 10,382 respondents, of whom 601 came from the five ethnic groups above. This relatively large sample size allows the study of a sub-group of the population, i.e. elders from minority ethnic heritage, which has been difficult in the past due to low cell counts.

The analysis examines pension protection in later life using three separate indicators: whether the individual is currently in receipt of a State Pension; whether they are currently in receipt of an occupational or private pension; and whether they are currently in receipt of Pension Credit. Table 1 shows the descriptive statistics for the sample. An individual's ethnicity was analysed using a self-reported variable with eight response categories (White British, Other White, Indian, Pakistani, Bangladeshi, Caribbean, African and Other Ethnic groups (includes Mixed, Other Asian and Other Ethnic group). This facilitated analysis of differentials between BME elders and the White British majority, as well as between individuals from different minority ethnic groups.

Figures $1-3$ show the percentage of men aged $6_{5}$ and over, and women aged 60 and over from different ethnic groups reporting being in receipt of income from these three sources. Key differentials are evident; between White British elders and BME elders; between elders from different BME groups; and between older men and women. In terms of receiving the State Pension, White British older men are most likely to be in receipt of the State Pension (94\%), compared to 67 per cent of African men. Among older women, the ethnic differences appear to be more prominent, with 91 per cent of White British women receiving the State Pension, compared to 62 per cent of African women (Figure 1).

Among older men, White British are most likely to be in receipt of an occupational/private pension $(84 \%)$, compared to 19 per cent of Pakistani men, 25 per cent of African men and 33 per cent of Bangladeshi men (Figure 2). Older women are overall less likely to be receiving an occupational/private pension compared to men, however, important ethnic 
T A в L E 1. Descriptive statistics of study population (aged State Pension Age and over)

\begin{tabular}{|c|c|c|c|c|c|c|c|c|c|c|c|c|}
\hline \multirow[b]{3}{*}{ Ethnic group } & \multicolumn{4}{|c|}{ In receipt of State Pension } & \multicolumn{4}{|c|}{$\begin{array}{l}\text { In receipt of occupational or private } \\
\text { pension }\end{array}$} & \multicolumn{4}{|c|}{ In receipt of Pension Credit } \\
\hline & \multicolumn{2}{|l|}{ Men } & \multicolumn{2}{|c|}{ Women } & \multicolumn{2}{|l|}{ Men } & \multicolumn{2}{|c|}{ Women } & \multicolumn{2}{|l|}{ Men } & \multicolumn{2}{|c|}{ Women } \\
\hline & $\%$ & $\mathrm{~N}$ & $\%$ & $\mathrm{~N}$ & $\%$ & $\mathrm{~N}$ & $\%$ & $\mathrm{~N}$ & $\%$ & $\mathrm{~N}$ & $\%$ & $\mathrm{~N}$ \\
\hline White British & $93 \cdot 5$ & $3,45^{8}$ & 91.1 & 5,877 & $83 \cdot 7$ & 3,243 & $49 \cdot 3$ & $5,4^{19}$ & $7 \cdot 3$ & 3,455 & $9 \cdot 5$ & 5,884 \\
\hline Other White & 89.1 & 93 & $83 \cdot 7$ & 187 & $64 \cdot 4$ & 89 & $4^{1 \cdot 4}$ & 173 & 8.8 & 93 & 8.1 & 187 \\
\hline Indian & 76.0 & 85 & $75 \cdot 5$ & $9^{6}$ & 60.4 & 80 & 30.4 & 90 & 8.0 & 85 & 12.2 & $9^{6}$ \\
\hline Pakistani & 76.5 & $4^{\circ}$ & $75 \cdot 0$ & $4^{1}$ & 18.8 & 37 & o & 37 & 11.1 & 40 & $5 \cdot 9$ & $4^{1}$ \\
\hline Bangladeshi & 70.0 & 26 & 80.0 & 20 & $33 \cdot 3$ & 24 & 40.0 & 20 & 20.0 & 26 & 20 & 20 \\
\hline Caribbean & $89 \cdot 3$ & 91 & $77 \cdot 1$ & 115 & 69.2 & 80 & $54 \cdot 5$ & 105 & 6.9 & 91 & 8.6 & 115 \\
\hline African & 66.7 & 27 & 61.5 & $3^{6}$ & 25.0 & 24 & 41.7 & $3^{1}$ & 11.1 & 27 & $7 \cdot 7$ & 37 \\
\hline Other Ethnic & 73.2 & 76 & 73.8 & 109 & 68.4 & 70 & 43.1 & 101 & $9 \cdot 5$ & 76 & 8.2 & 109 \\
\hline All & 92.7 & 3,896 & 90.5 & $6,4^{81}$ & 82.2 & 3,647 & 61.5 & 5,976 & $7 \cdot 5$ & 3,893 & $9 \cdot 5$ & $6,4^{89}$ \\
\hline
\end{tabular}

Source: Understanding Society $(2009-11)$. 


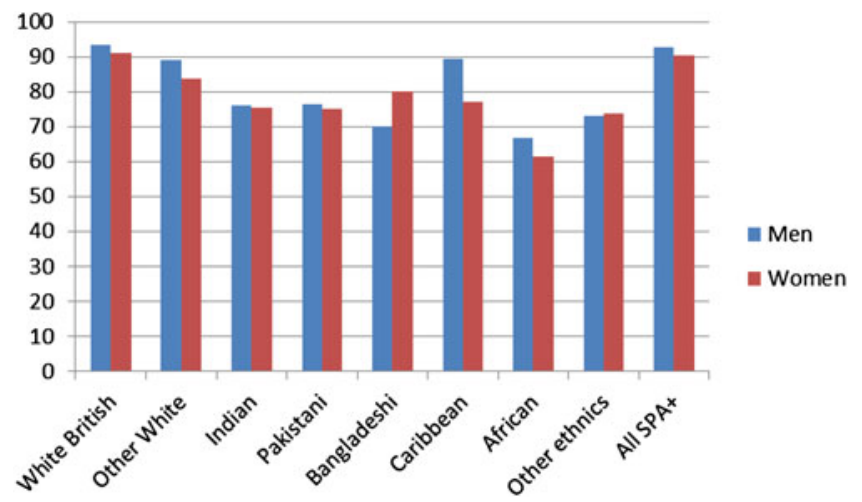

Figure 1. Percentage of older individuals receiving the State Pension, by ethnic group and gender, 2009-11.

Note: SPA+: State Pension Age and over. Significant at $p<0.001$

Source. Understanding Society $(2009-11)$.

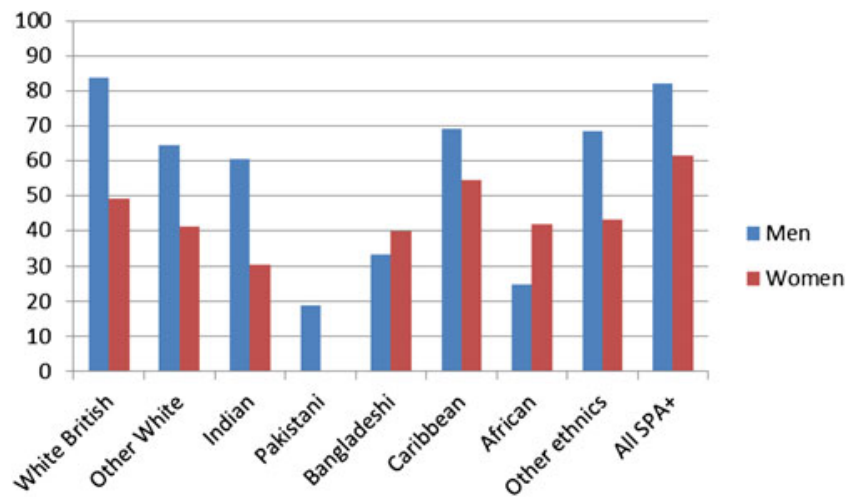

Figure 2. Percentage of older individuals receiving an occupational/private pension, by ethnic group and gender, 2009-11.

Note: SPA+: State Pension Age and over. Significant at $p<0.001$

Source: Understanding Society $(2009-11)$.

differences can also be noted. Older women from the Caribbean are the most likely to be receiving such pensions $(54.5 \%)$, reporting higher levels of receipt than White British women compared to 30 per cent of Indian women, while there are no Pakistani women in the sample in receipt of such pensions (Figure 2). For those being in receipt of Pension Credit, both men and women of Bangladeshi origin are the most likely to be in receipt of Pension Credit (20\%), while Caribbean men and Pakistani women are the least likely to be receiving this benefit $(7$ and $6 \%$, 


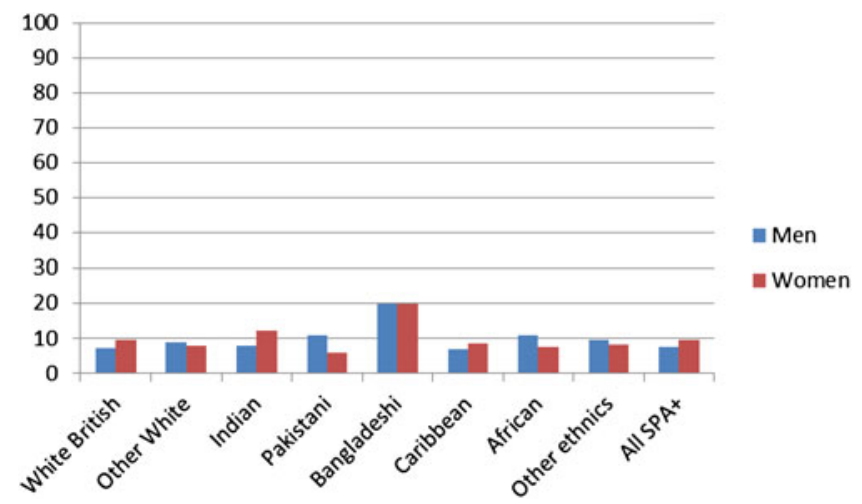

Figure 3. Percentage of older individuals receiving Pension Credit, by ethnic group and gender, 20O9 -11 .

Source. Understanding Society $(2009-11)$.

respectively) (Figure 3). Although indicative of patterns for the receipt of this benefit, probably due to low cell counts for this variable, the cross-tabulation of this relationship is not statistically significant.

Such differentials go some way towards measuring the impact of ethnicity on older persons' chances of having adequate pension protection, or highlighting the risk among particular groups of men and women, of having inadequate pension protection. Multivariate analysis using three separate binary logistic regression models helps to disentangle the relative importance of ethnicity in terms of older individuals' pension protection, taking into account key characteristics at the same time. As such, this analysis addresses the research question 'What are the characteristics (including ethnicity) associated with receiving a State Pension or an occupational/ private pension or Pension Credit?' Building on existing literature and Figures 1-3 which show significant gender differences in pension protection, the three regression models were also run separately for men and women, in order to understand the determinants of receiving a certain type of pension income in later life.

The explanatory variables used in the multivariate analysis reflect demographic characteristics (age, gender, marital status, living arrangements); health status (self-reported general health, report of a limiting long-standing illness); and socio-economic status (highest educational qualification, housing tenure, whether one has ever worked). In addition, the analysis controls for two factors which can affect individuals' employment status and history, and by extension, their eligibility for receiving different kinds of pension income. The first is whether an individual has been born in the UK, and if not, the length of time they have been in the UK (less than 10, 10-39, 
$4^{\mathrm{o}-49,} 5^{\mathrm{o}}$ or more years). Such an indicator is important to take into account, as existing literature shows cohort differences in the employment and savings behaviour of individuals from particular BME communities, such as the Pakistani and Bangladeshi (Nesbitt and Neary 2001), and second-generation Indians and Pakistanis being more likely to set up dual-earner households than their parents (Barnes and Taylor 2006). The second factor is whether an individual has difficulty speaking English on a day-to-day basis, drawing upon the evidenced link between fluency in English and employment prospects among non-White individuals (Dustmann and Fabbri 2003). The choice of other variables included in this part of the analysis is based on evidence included in existing literature showing, for example, the association between pension protection and gender (Foster 2013) or pension protection and working life history (Sefton et al. 2011); and the use of educational qualifications and housing tenure as proxies for older people's socio-economic status (Evandrou $2000 b$ ). Most of the variables were used in the analysis following minor merges of categories of the original variables. However, the derivation of certain variables is worth detailing further. In order to gain a balanced understanding between positive and negative self-reporting of general health, the original five-category variable (excellent, very good, good, fair, poor) was used to derive a three-category variable, which merged the three 'positive' categories into one 'good' category, and maintained the 'fair' and 'poor' categories. The construction of the variable indicating the reporting of a limiting long-standing illness was achieved using two separate variables, i.e. whether the respondent experiences limitations in their activities due to health and whether they face a long-standing illness in their everyday life. As the two variables are asked separately, the derived limiting long-standing illness variable includes a category of respondents who reported no long-standing illness but who still reported limitations in their everyday life. Tables $2-4$ present the final models of the regression analysis, which include the explanatory variables exhibiting a statistically significant relationship with the outcome variable in each case, i.e. the receipt of different types of pension income.

\section{The association between ethnicity and the receipt of pension income}

Table 2 shows that ethnicity has a significant effect on older individuals' chances of being in receipt of the State Pension. The model for both men and women indicates that Pakistani and African individuals, and individuals from Other Ethnic groups are significantly less likely to receive a State Pension than the White British majority. Beyond the impact of 
T A B L E 2. Determinants of currently receiving a State Pension (final model)

\begin{tabular}{|c|c|c|c|c|}
\hline & $\%$ & Both genders & Male & Female \\
\hline & & \multicolumn{3}{|c|}{ Odds ratios } \\
\hline Receiving State Pension $\left(\mathrm{N}=9,39^{6}\right)$ & 90.30 & & & \\
\hline Not receiving State Pension $(\mathrm{N}=997)$ & $9 \cdot 70$ & & & \\
\hline \multicolumn{5}{|l|}{ Age: } \\
\hline Below 75 (Ref.) & $67 \cdot 39$ & 1 & 1 & 1 \\
\hline Age above 75 & 32.61 & $1.27 * *$ & 1.15 & $1.36 * *$ \\
\hline \multicolumn{5}{|l|}{ Gender: } \\
\hline Male (Ref.) & $37 \cdot 55$ & 1 & & \\
\hline Female & 62.45 & $0.77^{* * *}$ & & \\
\hline \multicolumn{5}{|l|}{ Marriage: } \\
\hline Married (Ref.) & 59.09 & 1 & 1 & 1 \\
\hline Single never married & 5.22 & 0.90 & 0.83 & 0.95 \\
\hline Divorced/separated & 11.37 & $1.30 *$ & 1.02 & $1.39 *$ \\
\hline Widowed & $24 \cdot 31$ & 1.08 & 1.10 & 1.06 \\
\hline \multicolumn{5}{|l|}{ Housing tenure: } \\
\hline Own outright (Ref.) & 69.24 & 1 & 1 & 1 \\
\hline Own with mortgage & 8.82 & $0.78^{*}$ & 0.90 & $0.75^{*}$ \\
\hline Social rented & $17 \cdot 32$ & 0.95 & 0.99 & 0.94 \\
\hline Rent privately & 3.99 & $0.63^{* *}$ & $0.4^{6 * *}$ & 0.74 \\
\hline Other & 0.63 & 1.10 & 0.72 & 1.46 \\
\hline \multicolumn{5}{|l|}{ Ethnicity: } \\
\hline White British (Ref.) & 89.97 & 1 & 1 & 1 \\
\hline Other White & 2.64 & 0.76 & $0.5^{\circ}$ & 0.90 \\
\hline Indian & 1.74 & 0.67 & $0.33^{*}$ & 0.98 \\
\hline Pakistani & 0.78 & $0.48^{*}$ & $0.22 * *$ & 0.73 \\
\hline Bangladeshi & 0.44 & 0.54 & $0.17 * *$ & 1.24 \\
\hline Caribbean & 1.98 & 0.61 & $0.4^{2}$ & 0.65 \\
\hline African & 0.61 & $0.4^{*}$ & $0.14^{* * *}$ & 0.84 \\
\hline Other Ethnic & 1.84 & $0.50^{* *}$ & $0.27^{* *}$ & 0.65 \\
\hline \multicolumn{5}{|l|}{ Self-rated general health: } \\
\hline Positive (Ref.) & 63.79 & 1 & 1 & 1 \\
\hline Fair & 23.19 & $0.78^{* *}$ & 0.88 & $0.73^{* *}$ \\
\hline Poor & 13.02 & $0.59 * * *$ & 0.72 & $0.52^{* * *}$ \\
\hline \multicolumn{5}{|l|}{ Report of limiting long-standing illness: } \\
\hline No (Ref.) & 22.63 & 1 & 1 & 1 \\
\hline Long-standing illness but not limiting & $9 \cdot 5^{2}$ & 1.04 & 0.93 & 1.09 \\
\hline Long-standing illness and limiting & 48.69 & $1.48^{* * * *}$ & 1.19 & $1.63^{* * *}$ \\
\hline No long-standing illness but has limitations & 19.17 & 1.11 & 1.02 & 1.14 \\
\hline \multicolumn{5}{|l|}{ Ever worked: } \\
\hline Yes (Ref.) & 78.73 & 1 & 1 & 1 \\
\hline Missing & 14.49 & $0.29 * * *$ & $0.25^{* * *}$ & $0.31^{* * *}$ \\
\hline No & 6.78 & $0.5^{8 * * *}$ & $0.59 *$ & $0.54^{* * *}$ \\
\hline \multicolumn{5}{|l|}{ Been in the United Kingdom (UK): } \\
\hline Born in the UK (Ref.) & 89.24 & 1 & 1 & 1 \\
\hline Less than 10 years & 0.29 & $0.06 * * *$ & $0.03^{* *}$ & $0.06 * * *$ \\
\hline $10-39$ years & 2.45 & $0.3^{* * * *}$ & 0.45 & $0.30^{* * *}$ \\
\hline $40-49$ years & 4.01 & 0.82 & 1.28 & 0.74 \\
\hline $5^{0+}$ years & 4.00 & 0.72 & 1.54 & $0.54^{* *}$ \\
\hline
\end{tabular}

Notes: $\mathrm{N}=10,393$. Ref.: reference category. Highest educational qualification was excluded from the final model as it was not statistically significant.

Source: Understanding Society $(2009-11)$, authors' calculations.

Significance levels: $* p<0.05,{ }^{* *} p<0.01, * * * p<0.001$. 
T A B LE 3. Determinants of currently receiving an occupational or private pension (final model)

$\%$ Both genders Male $\quad$ Female

Receiving an occupational/private pension

60.6

Odds ratios

$(\mathrm{N}=5,854)$

Not receiving an occupational/private pension

$(\mathrm{N}=3,783)$

Age:

Below 75 (Ref.)

Age above 75

Gender:

Male (Ref.)

Female

Marital status:

Married (Ref.)

Single never married

Divorced/separated

Widowed

Education:

Degree (Ref.)

Other high qualification

A-level

GCSE

Other qualification

No qualifications

Housing tenure:

Own outright (Ref.)

Own with mortgage

Social rented

Rent privately

Other

Ethnicity:

White British (Ref.)

Other White

Indian

Pakistani

Bangladeshi

Caribbean

African

Other Ethnic

Self-rated general health:

Positive (Ref.)

Fair

Poor

Report of limiting long-standing illness:

No (Ref.)

Long-standing illness but not limiting

Long-standing illness and limiting

No long-standing illness but has limitations

Ever worked:

Yes (Ref.)

Missing

No

$39 \cdot 4$

\begin{tabular}{|c|c|c|c|}
\hline 68.1 & 1 & 1 & 1 \\
\hline 31.9 & o. $86^{* *}$ & 1.00 & $0.77^{* * * *}$ \\
\hline $37 \cdot 9$ & 1 & 1 & 1 \\
\hline 62.1 & $0.20^{* * *}$ & & \\
\hline 60.3 & 1 & 1 & 1 \\
\hline 5.2 & $1.37 * *$ & $0.51 * * *$ & $2.56^{6 * * *}$ \\
\hline 11.2 & 1.12 & 0.77 & $1.25^{*}$ \\
\hline 23.4 & 1.06 & 0.79 & $1.21 * *$ \\
\hline 10.4 & 1 & 1 & 1 \\
\hline 9.0 & 0.83 & 0.96 & $0.74 *$ \\
\hline 4.1 & $0.54^{* * *}$ & $0.49^{* *}$ & $0.57 * *$ \\
\hline 10.9 & $0.5^{2 * * *}$ & $0.62 *$ & o. 49 **** \\
\hline 8.9 & $0.37^{* * *}$ & $0.62 *$ & $0.1^{* * * *}$ \\
\hline $5^{6.7}$ & $0.28 * * *$ & $0.46^{* * *}$ & $0.24 * * *$ \\
\hline $69 \cdot 7$ & 1 & 1 & 1 \\
\hline 9.0 & 0.95 & 1.16 & 0.92 \\
\hline 16.7 & $0.4^{6 * * *}$ & $0.33^{* * *}$ & $0.55^{* * * *}$ \\
\hline 4.0 & $0.5 \mathrm{O}^{* * *}$ & $0.28 * * *$ & $0.71^{*}$ \\
\hline 0.6 & 0.97 & 0.57 & 1.32 \\
\hline 90.0 & 1 & 1 & 1 \\
\hline 2.7 & o. $66^{*}$ & $0.43^{* *}$ & 0.82 \\
\hline 1.8 & $0.53^{*}$ & $0.37^{*}$ & 0.73 \\
\hline 0.8 & $0.10^{* * *}$ & $0.09 * * *$ & $0.08 *$ \\
\hline 0.5 & $0.19 * * *$ & $0.07^{* * * *}$ & 1.15 \\
\hline 1.9 & 1.15 & 0.71 & 1.53 \\
\hline o. 6 & $0.4^{*}$ & $0.15^{* *}$ & 1.87 \\
\hline 1.8 & 0.84 & 0.53 & 1.09 \\
\hline $64 \cdot 3$ & 1 & 1 & 1 \\
\hline 23.1 & $0.82 * *$ & o. $67^{* * *}$ & 0.87 \\
\hline 12.6 & $0.64 * * *$ & $0.63^{* *}$ & $0.61^{* * *}$ \\
\hline 23.1 & 1 & 1 & 1 \\
\hline 9.7 & $1.21 \%$ & 1.07 & $1.25^{*}$ \\
\hline 48.0 & 1.10 & 1.05 & 1.10 \\
\hline $19 \cdot 3$ & 1.04 & 0.89 & 1.10 \\
\hline 78.4 & 1 & 1 & 1 \\
\hline 14.8 & $0.54^{* * *}$ & $0.47^{* * *}$ & $0.54^{* * * *}$ \\
\hline 6.9 & o. 68 *** & $0.70^{*}$ & $0.67 * * *$ \\
\hline
\end{tabular}




\begin{tabular}{|c|c|c|c|c|}
\hline & $\%$ & Both genders & Male & Female \\
\hline \multicolumn{5}{|c|}{ Been in the United Kingdom (UK): } \\
\hline Born in the UK (Ref.) & $89 \cdot 3$ & 1 & 1 & 1 \\
\hline Less than 10 years & 0.3 & $0.09 * * *$ & $0.07^{*}$ & $0.09 * *$ \\
\hline $10-39$ years & 2.5 & $0.5 \mathrm{O}^{* * *}$ & $0.42^{*}$ & $0.47^{* *}$ \\
\hline $40-49$ years & 4.0 & 0.85 & 1.15 & 0.70 \\
\hline $5^{\mathrm{O}+\text { years }}$ & $3 \cdot 9$ & 0.84 & $0.89 * *$ & 0.91 \\
\hline \multicolumn{5}{|c|}{ Difficulty speaking day-to-day English: } \\
\hline No (Ref.) & 98.6 & 1 & 1 & 1 \\
\hline Yes & 1.4 & $0.43^{* *}$ & $0.20^{* *}$ & 0.59 \\
\hline
\end{tabular}

Notes: N=9,637. Ref.: reference category. GCSE: General Certificate of Secondary Education. Source. Understanding Society $(2009-11)$, authors' calculations.

Significance levels: $* p<0.05, * * p<0.01, * * * p<0.001$.

ethnicity, the model shows that one's chances of being in receipt of the State Pension are also affected by other demographic, health and socio-economic characteristics. Such chances increase with age, as women are 23 per cent less likely than men to be in receipt of the State Pension, while divorced/ separated individuals are 30 per cent more likely than married individuals to be receiving a State Pension. In terms of socio-economic variables, older individuals' odds of being in receipt of a State Pension are highest for owner-occupiers and those who have ever worked. Crucially, when considering the impact of ethnicity, individuals who have spent less than ten years, or between ten and 39 years, in the UK are 94 and 64 per cent less likely, respectively, than those born in the UK to be in receipt of a State Pension, indicating a 'migration pension penalty'. Finally, the report of fair or poor health reduces one's odds of receiving the State Pension, while individuals who reported a limiting long-standing illness are 48 per cent more likely than those not reporting an illness, to be in receipt of a State Pension. Education was not statistically significant in the final models (both in the model for men and women together, and in the separate gender models), and as such, education is not added in the final models for this outcome variable.

When the model was run separately for men and women, the adverse effect of ethnicity among men became more evident. Indian, Pakistani, Bangladeshi and African men, as well as men from Other Ethnic groups, are less likely to be receiving a State Pension than White British men, while such an adverse effect is not statistically significant for women from BME communities. No significant effects are found for men in terms of age and marital status, whereas among women, older age is associated with higher odds of receiving a State Pension, and the odds of receiving 
Ethnic elders and pension protection 1039

T A B L 4 . Determinants of currently receiving Pension Credit (final model)

\begin{tabular}{|c|c|c|c|c|}
\hline & $\%$ & Both genders & Male & Female \\
\hline & & \multicolumn{3}{|c|}{ Odds ratios } \\
\hline Receiving Pension Credit $(\mathrm{N}=921)$ & 8.9 & & & \\
\hline Not receiving Pension Credit $(\mathrm{N}=9,469)$ & 91.1 & & & \\
\hline \multicolumn{5}{|l|}{ Age: } \\
\hline Below 75 (Ref.) & $67 \cdot 4$ & 1 & 1 & 1 \\
\hline Age above 75 & 32.6 & 1.03 & 1.03 & 1.01 \\
\hline \multicolumn{5}{|l|}{ Gender: } \\
\hline Male (Ref.) & 37.5 & 1 & & \\
\hline Female & 62.5 & 1.04 & & \\
\hline \multicolumn{5}{|l|}{ Marital status: } \\
\hline Married (Ref.) & $59 \cdot 1$ & 1 & 1 & 1 \\
\hline Single never married & 5.2 & $2.90^{* * *}$ & $2.10^{* * * *}$ & $4.07^{* * *}$ \\
\hline Divorced/separated & 11.4 & $3.84^{* * *}$ & $1.7 \mathrm{O}^{* *}$ & $6.4^{6 * * *}$ \\
\hline Widowed & $24 \cdot 3$ & $2.42^{* * *}$ & 1.30 & $3.59^{* * *}$ \\
\hline \multicolumn{5}{|l|}{ Education: } \\
\hline Degree (Ref.) & 10.3 & 1 & 1 & 1 \\
\hline Other high & 9.0 & 1.28 & 0.75 & $1.5^{1}$ \\
\hline A-level & 3.9 & $2.09 *$ & 2.36 & 2.08 \\
\hline GCSE & 10.6 & $1.85^{*}$ & 1.88 & 2.01 \\
\hline Other qualification & $9 \cdot 0$ & $3.11 * * *$ & $3.54^{* * *}$ & $3.01 * *$ \\
\hline No qualification & 57.1 & $3 \cdot 32^{* * *}$ & $2.79 * * *$ & $4.01 * * *$ \\
\hline \multicolumn{5}{|l|}{ Housing tenure: } \\
\hline Own outright (Ref.) & 69.2 & 1 & 1 & 1 \\
\hline Own with mortgage & 8.8 & $1.99^{* * *}$ & $1.94^{*}$ & $1.92^{* * * *}$ \\
\hline Social rented & $17 \cdot 3$ & $3.68 * * *$ & $5.15^{* * * *}$ & $3.13^{* * *}$ \\
\hline Rent privately & 4.0 & $3.19 * * *$ & $5.21 * * *$ & $2.47^{* * *}$ \\
\hline Other & 0.6 & 1.64 & 1.44 & 1.98 \\
\hline \multicolumn{5}{|l|}{ Ethnicity: } \\
\hline White British (Ref.) & 90.0 & 1 & 1 & 1 \\
\hline Other White & 2.6 & $1.4^{1}$ & $3 \cdot 31^{* *}$ & o.89 \\
\hline Indian & 1.7 & $2.30 *$ & $8.62 * *$ & 1.16 \\
\hline Pakistani & 0.8 & 0.91 & 4.20 & 0.32 \\
\hline Bangladeshi & 0.4 & 1.63 & $6.63^{*}$ & 0.59 \\
\hline Caribbean & 2.0 & 0.77 & $3 \cdot 31$ & $0.4^{2}$ \\
\hline African & o.6 & 1.08 & 4.53 & 0.45 \\
\hline Other Ethnic & 1.8 & 1.06 & $5.11 * *$ & $0.5^{\mathrm{O}}$ \\
\hline \multicolumn{5}{|l|}{ Report of limiting long-standing illness: } \\
\hline No (Ref.) & 22.6 & 1 & 1 & 1 \\
\hline Long-standing illness but not limiting & $9 \cdot 5$ & 1.30 & 1.03 & $1.4^{1}$ \\
\hline Long-standing illness and limiting & 48.7 & $1.75^{* * *}$ & $1.93^{* * *}$ & $1.60^{* *}$ \\
\hline No long-standing illness but has limitations & 19.1 & $1.33^{*}$ & 1.46 & 1.23 \\
\hline \multicolumn{5}{|l|}{ Ever worked: } \\
\hline Yes (Ref.) & 78.7 & 1 & 1 & 1 \\
\hline Missing & 14.5 & $0.20^{* * * *}$ & $0.32^{* * *}$ & $0.17^{* * *}$ \\
\hline No & 6.8 & $0.68 *$ & $0.30^{* *}$ & 0.87 \\
\hline \multicolumn{5}{|l|}{ Been in the United Kingdom (UK): } \\
\hline Born in the UK (Ref.) & 89.2 & 1 & 1 & 1 \\
\hline Less than 10 years & 0.3 & 0.00 & 0.00 & 0.00 \\
\hline $10-39$ years & 2.5 & 1.16 & 0.36 & 1.98 \\
\hline $40-49$ years & 4.0 & 1.01 & $0.29 *$ & $1.6_{5}$ \\
\hline
\end{tabular}


T A B LE $4 \cdot$ (Cont.)

\begin{tabular}{lclll}
\hline & $\%$ & Both genders & Male & Female \\
\hline $5^{\text {o+ years }}$ & 4.0 & $0.55^{*}$ & $0.17^{* * *}$ & 0.82
\end{tabular}

Notes: $\mathrm{N}=10$,390. Ref.: reference category. GCSE: General Certificate of Secondary Education. Self-reported general health was excluded from the final model as it was not statistically significant.

Source: Understanding Society (2009-11), authors' calculations.

Significance levels: $* p<0.05, * * p<0.01, * * * p<0.001$.

State Pension income among divorced/separated women are 1.39 times the odds among married women. In terms of socio-economic variables, men who rent their property privately and women who own their property with a mortgage are less likely to be receiving a State Pension than men and women owner-occupiers, respectively. The results also show the importance of employment: older men and women who have never worked are 41 and $4^{6}$ per cent, respectively, less likely to be receiving a State Pension. Finally, health appeared to have an effect in the women's model, but not in the men's model. The odds of receiving a State Pension among older women reporting fair or poor health are 0.73 and $0.5^{2}$ times, respectively, the odds among older women reporting good health, while older women reporting a limiting long-standing illness are 63 per cent more likely to be receiving State Pension income than those not reporting an illness. Finally, the disadvantage faced by migrants is also evident, especially among women: men and women who have spent less than ten years in the UK are 97 and 94 per cent, respectively, less likely to be receiving a State Pension, compared to their counterparts who were born in the UK,

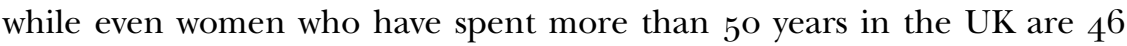
per cent less likely than women born in the UK to be receiving a State Pension.

The results indicate that ethnicity also has a significant effect on older individuals' chances of being in receipt of an occupational or private pension (Table 3). The model including both men and women shows that most non-White British groups are less likely to receive an occupational or private pension. Pakistani and Bangladeshi persons are the least likely to receive an occupational or private pension compared to the White British majority (o.10 and 0.19 times, respectively). Being over 75 , female, with educational qualifications lower than a degree, renting from the social or private sector, reporting fair or poor general health, having never worked, having spent up to 39 years in the UK (compared to having been born in the UK) and, finally, having difficulty speaking day-to-day English, are associated with lower odds of receiving an occupational or private pension. 
When the analysis was run separately by gender, the results were found to be broadly similar (e.g. in terms of the effect of education, housing tenure and whether one has ever worked), although certain differences between men and women are evident. Older age appears to be a negative factor for women, but not for men (odds ratio $(\mathrm{OR})=0.77$ compared to the younger group). Being single never married, divorced/separated or widowed is associated with higher odds of receiving an occupational or private pension for women, but with lower odds for men. For men, all BME groups (except for the Caribbean and Other Ethnic groups where results are not significant) are less likely to be receiving an occupational or private pension than the White British, whereas for women such low odds are only statistically significant for Pakistani women $(\mathrm{OR}=0.08)$. Finally, the negative impact of having difficulty with speaking English on a day-to-day basis is evident for older men, but not women.

The results of the different factors associated with the receipt of Pension Credit between the White British majority and ethnic minorities are illustrated in Table 4. From the model including both men and women combined, only Indian individuals are significantly more likely to be receiving Pension Credit than the White British majority $(\mathrm{OR}=2.30$ compared to White British). It is important to note that the differences in the eligibility rules for receiving Pension Credit, which was designed to 'top-up' the income of poorer pensioners, means that the groups who were more likely to receive State Pensions and occupational pensions (e.g. White British) were shown to be less likely to be in receipt of Pension Credit, while the opposite is the case for many individuals from BME communities. There are no age and gender effects; while single never married, divorced/ separated or widowed older people are more likely to be receiving Pension Credit than those who are married (2.90, 3.84 and 2.42 times, respectively). In terms of socio-economic variables, having educational qualifications lower than a degree, and either owning one's home with a mortgage or renting (privately or socially) are associated with higher odds of receiving Pension Credit, while having never worked is associated with lower odds. Finally, the report of a limiting long-standing illness increases one's odds of receiving Pension Credit (the self-reported health status variable was not statistically significant in this model).

The separate models for men and women show that demographic, socioeconomic and health determinants have a similar effect on men's and women's chances of receiving Pension Credit, although the strength of such effects varies between the two genders. Being single or divorced/separated is associated with higher odds of receiving Pension Credit, but such an effect is stronger for women than for men, while widowhood has a positive effect on such odds for women only. Slight differences in the strength of the 
coefficients also characterise the impact of socio-economic characteristics: for example, having no educational qualifications is associated with higher odds of receiving Pension Credit among women than among men, while renting privately is associated with higher odds among men than among women. Having never worked is associated with lower odds for men only, while the report of a limiting long-standing illness is associated with higher odds of receiving Pension Credit for both men and women. The effect of ethnicity appears to be positive on Other White, Indian and Other Ethnic men's chances of receiving Pension Credit, but not on women's chances.

The calculation of predicted probabilities for each of the three outcome variables (State Pension, occupational/private pension, Pension Credit) helps to distil the effect of ethnicity further. The calculation uses the strongest predictors associated with the outcome variable in each case (Figures $4^{-6)}$. The three figures show the clear differences between ethnic groups in terms of receiving pension income from different sources. For example, in Figure 4, White British individuals, followed by Other White, Indian and Caribbean individuals, show the highest likelihood of receiving the State Pension, while Pakistani and African individuals, followed by the Bangladeshi group, show the lowest likelihood. The receipt of an occupational/private pension is most likely among the White British, Caribbean, Other White and Other Ethnic groups, closely followed by the Indian group, whereas the Pakistani and Bangladeshi groups are the least likely to be receiving such pensions. Finally, Figure 6 shows that Indian and Bangladeshi individuals, closely followed by the Other White, Pakistani, African and Other Ethnic groups, are the most likely to be receiving Pension Credit.

The analysis in this paper includes a number of limitations which should be taken into account. Firstly, the data-set does not distinguish information on the precise amount received from different sources (e.g. amount received only from State Pension). As a result, it is not possible to further our understanding of differences in the disadvantage faced by particular ethnic groups. Secondly, the receipt of Pension Credit suffers from significant under-reporting, which is reflected in the survey data we have analysed. Although it was not possible to distinguish for different ethnic groups, when we compared administrative data from the Department for Work and Pensions on the caseload for Pension Credit receipt (including both Guarantee and Savings credit) with Census 2011 data on the older population, we found that such data points to 22.83 per cent of women aged 60 or over and 32.83 per cent of men aged $6_{5}$ or over receiving Pension Credit, compared to 9.5 and 7.5 per cent in our analysis. However, when we compared the administrative data for the receipt of the Guarantee element of 


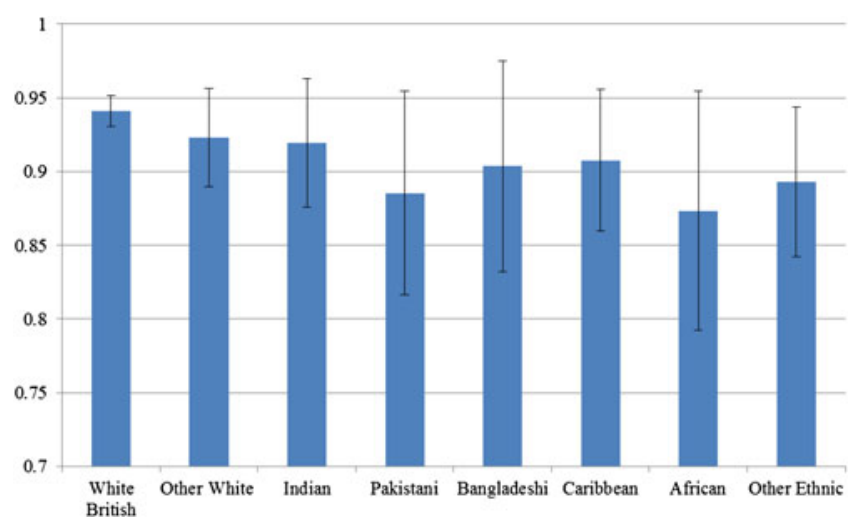

Figure 4. Predicted probabilities and 95 per cent confidence intervals of receiving a State Pension by ethnicity.

Note: Reference category: aged below 75, married, owning home outright, educated to degree level, reporting positive self-rated health, no limiting long-standing illness, having worked and born in the United Kingdom.

Source. Understanding Society (2009-11), authors' calculations.

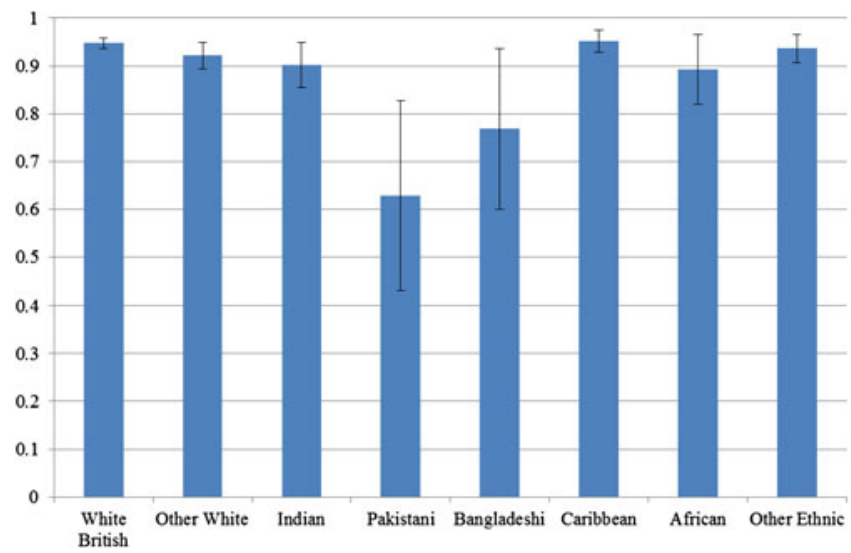

Figure 5. Predicted probabilities and 95 per cent confidence intervals of receiving an occupational/private pension by ethnicity.

Note. Reference category: aged below 75, married, owning home outright, educated to degree level, reporting positive self-rated health, no limiting long-standing illness, having worked and born in the United Kingdom.

Source. Understanding Society (2009-11), authors' calculations.

Pension Credit only, which is less likely to be under-reported than the Savings element, the survey data which we analysed was more consistent with the administrative data $(7.45 \%$ of women; $5.49 \%$ of men). These figures confirm a significant degree of under-reporting in the receipt of 


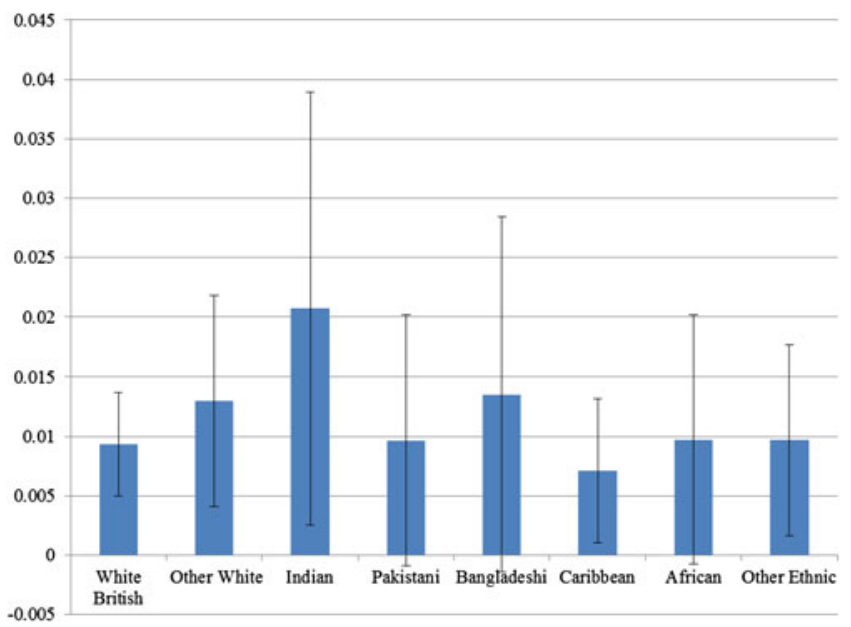

Figure 6. Predicted probabilities and 95 per cent confidence intervals of receiving Pension Credit by ethnicity.

Note: Reference category: aged below 75, married, owning home outright, educated to degree level, no limiting long-standing illness, having worked and born in the United Kingdom.

Source: Understanding Society (2009-11), authors' calculations.

Pension Credit in the survey data, which in all likelihood underestimates the percentage of older people receiving Pension Credit and therefore the percentage of individuals on low incomes in later life.

\section{Discussion and conclusion}

This paper examined the association between ethnicity and older individuals' receipt of three different types of pension income (State, occupational/private, Pension Credit), taking into account a range of demographic, socio-economic and health characteristics. The results contribute important empirical evidence of the relative disadvantage in terms of pension protection faced by older individuals from particular BME communities. Four key points emanate from the research relating to: firstly, the lower likelihood of certain BME groups receiving an occupational/private pension; secondly, the higher likelihood of individuals from particular BME communities receiving Pension Credit; thirdly, gender differences across and within ethnic groups; and finally, the contribution of factors relating to the migrant status of BME groups to the analysis of pension protection.

In the first instance, the paper highlights that individuals from all ethnic groups (except for Caribbeans for whom the results were not significant) are less likely to be receiving the State Pension or an occupational/private 
pension. This finding is in line with official government data from the Pensioners Income Series, and is also compatible with the results from qualitative interviews with individuals up to 62 years old by Gough and Adami's (2013) findings. The paper provides a more up-to-date empirical picture of the differences between different ethnic groups (e.g. Bangladeshi and Pakistani individuals overall fare worse than Other White, Indian or African individuals), adding to the body of work from the 199 os including Burton (1996) and Berthoud (1998). Two important points are worth noting with regard to this: firstly, the differences between ethnic groups remain even after controlling for a range of demographic, health and socio-economic characteristics; and secondly, such differences do not appear to have diminished even after policy reforms relaxing the eligibility criteria for the receipt of the State Pension, and even after concerted policy efforts to promote occupational pensions in the labour market. Importantly for the population under study, this first finding is a reminder that employment patterns over one's lifecourse have a direct bearing on one's pension receipt in later life, and that pension protection of individuals from BME communities needs to accommodate a higher-than-average self-employment rate in such groups (Vlachantoni et al. 2015).

The results which indicate higher odds among certain ethnic groups of receiving Pension Credit compared to White British individuals (i.e. Indian individuals; and Indian, Bangladeshi and Other Ethnic men when separated by gender), are a novel contribution of this paper to existing literature. To our knowledge, up-to-date empirical evidence implying a greater reliance on Pension Credit on the part of ethnic minority groups relative to the White British group only exists in the form of the Department for Work and Pensions' Pensioner Income Series (Department for Work and Pensions 2015). Even so, the Department for Work and Pensions data cluster individuals from more than one BME group, and from the published data it is not possible to distinguish between different ethnic groups. Previous research points to a higher likelihood of receiving means-tested benefits among Pakistani and Bangladeshi individuals (Berthoud 1998; Burton 1996). Our paper updates such findings which are 20 years old, and adds empirical findings to the perspectives of BME older people themselves on the issue of pension protection (Gough and Hick 2009). Building on such literature, the analysis in this paper presents a more nuanced picture, which shows that, when one considers men and women together, the receipt of Pension Credit is statistically associated with being of Indian or Bangladeshi heritage (at the $p<0.1$ level), compared to being White British. In this respect, the paper also shows that older individuals who are less likely to be in receipt of the State Pension or an occupational/private pension are more likely to be in receipt of Pension Credit, and vice versa. What is more, individuals with a 
greater risk of receiving Pension Credit, and a lower risk of receiving pensions from other sources, are more likely to be from specific BME communities, reflecting a triple jeopardy within the pension system.

Another original contribution of the paper is reflected in findings which point to continued gender differences in terms of the receipt of a pension from different sources but also within ethnic groups, that is women are overall less likely than men to be receiving State Pensions or occupational/ private pensions but when separated by gender, the vast majority of BME women's results are not statistically significant. More specifically, controlling for ethnicity and a host of other characteristics, older women are less likely than men to be receiving a State Pension or an occupational/private pension, and slightly more likely $(\mathrm{OR}=1.04)$ to be receiving Pension Credit, although the latter result is not statistically significant. Focusing on particular ethnic groups, gender differences relating to private pensions only and disadvantaging women from certain BME groups, have been shown in much earlier literature (Ginn and Arber 2001), and our finding that Pakistani women are less likely than White British women to be receiving an occupational/private pension are in line with such results $(\mathrm{OR}=0.08)$. Taken together, these findings call for further investigation into gender differences, which would require the pooling together of several years' data in order to focus on particular ethnic groups and understand ethnic-specific gender disadvantages in this area.

Finally, this paper, to the best of our knowledge, is the first to take individuals' migrant status into account, and indicates that having been born outside the UK reduces one's odds of receiving any of the three types of pension income. In the case of Pension Credit, such a finding may indicate a 'hierarchy' of disadvantage within the ethnic minority population, with those born in the UK being more likely to receive Pension Credit, possibly because of being more likely to claim it. Government statistics which take clustered ethnicity into account do show that 7 per cent of 'eligible non-recipients' of Pension Credit are Asian/Asian British (compared to $85 \%$ who are White), compared with 4 per cent of eligible recipients who are Asian/Asian British (compared to $87 \%$ who are White) (Department for Work and Pensions 2012; Office for National Statistics 2012), however such statistics are less indicative of eligibility within different ethnic groups.

The combination of these characteristics points to the need for nuanced social policies aimed at improving the financial wellbeing of older individuals from ethnic minorities in the UK. The most recent government evidence (Office for National Statistics and Department for Work and Pensions 2015) showed that approximately 14 per cent of all pensioners found themselves in relative poverty (below 6o per cent of median income after housing costs), but this percentage was 23 per cent among 
Indian pensioners and 24 per cent among Black/African/Caribbean/Black British pensioners. Such groups' lower chances of receiving the State Pension or an occupational/private pension no doubt contribute to the degree of vulnerability experienced in later life, as do their higher chances of receiving Pension Credit. Current cohorts of older people may benefit from greater encouragement to claim for welfare benefits they are entitled to, as well as a strengthening the value of the State Pension.

Beyond the British context, this paper encourages us to consider the combined effect on pension protection in later life, of ethnicity and time spent by older BME individuals in the 'destination' country following their migration earlier in the lifecourse. Ensuring adequacy in social security for migrants in later life is an increasing policy challenge which permeates and extends beyond national borders (Meyer, Bridgen and Andow 2013; van Ginneken 2013). A large body of literature has considered the reasons for migration over one's lifecourse (e.g. economic, joining family) and the implications of the nature of migration for one's wellbeing in later life (see e.g. Blakemore 1999; Cook 2010). The results in this paper, particularly those relating to the combined impact of ethnic origin, having been born in the UK (or not) and language fluency, show that reaching later life in a 'destination' country can be financially disadvantageous compared to older individuals who have been born in that country. Much of this disadvantage directly relates to one's employment patterns over the lifecourse, an area where the diversity of BME groups, and its adverse effect on pension rights, has long been evidenced (Steventon and Sanchez 2008). However, a substantial part of such disadvantage relates to the rules of the pensions and benefit system of the host country, which are also amenable to change with a view to providing a more inclusive society for older individuals from BME communities.

\section{Acknowledgements}

The analysis in this paper is funded under the project 'Pension Protection for Minority Ethnic Groups in Britain: Determinants, Prospects and Policy Implications', funded by the Economic and Social Research Council Secondary Data Analysis Initiative (grant number ES/Koo3518/1).

\section{References}

Allmark, P., Salway, S., Crisp, R. and Barley, R. 2010. Ethnic Minority Customers of the Pension, Disability and Carers Service: An Evidence Synthesis. Department for Work and 
Pensions Research Report 684. Available online at https://www.gov.uk/government/uploads/system/uploads/attachment_data/file/2 14455/rrep684.pdf [Accessed 13 January 2014].

Bardasi, E. and Jenkins, S. 2010. The gender gap in private pensions. Bulletin of Economic Research, 62, 4, 343-63.

Barnes, H. and Taylor, R. 20o6. Work, saving and retirement among ethnic minorities: a qualitative study. Department for Work and Pensions Research Report 396, Her Majesty's Stationery Office, Norwich, UK.

Berthoud, R. 1998. The Incomes of Ethnic Minorities. Institute for Social and Economic Research. Available online at https://www.iser.essex.ac.uk/files/iser_reps/pdf/ oo1.pdf [Accessed 13 January 2014].

Blakemore, K. 1999. International migration in later life: social care and policy implications. Ageing $\mathcal{E}$ Society, 19, 6, 761-74.

Boreham, R., Boldysevaite, D. and Killpack, C. 2012. UKHLS Wave 1 technical report. National Centre for Social Research, Institute for Social and Economic Research, Colchester, UK.

Burton, D. 1996. Ethnicity and consumer financial behaviour: a case study of British Asians in the pension market. International Journal of Bank Marketing, 14, 7, 21-31.

Burton, J., Nandi, A. and Platt, L. 2008. Who are the UK's ethnic minority groups? Issues of identification and measurement in a longitudinal study. ISER Working Paper 2008-26, Institute for Social and Economic Research, Colchester, UK.

Cook, J. 2010. Exploring older women's citizenship: understanding the impact of migration in later life. Ageing $\mathcal{E}$ Society, 3o, 2, 253-73.

Department for Work and Pensions 201 2. Income Related Benefits: Estimates of Take-up in 2009-10. Available online at https://www.gov.uk/government/collections/ income-related-benefits-estimates-of-take-up-2 [Accessed 13 January 2014 ].

Department for Work and Pensions 2015. The Pensioners' Income Series, United Kingdom, ${ }_{2013 / I 4}$ https://www.gov.uk/government/statistics/pensioners-incomes-seriesfinancial-year-201314 [Accessed 19 August 2015].

Dustmann, C. and Fabbri, F. 2003. Language proficiency and labour market performance of immigrants in the UK. The Economic Journal, 113, 489, 695-717.

Evandrou, M. 2000a. Ethnic inequalities in health in later life. Health Statistics Quarterly, 8, Winter, 20-8.

Evandrou, M. 200o $b$. Social inequalities in later life: the socio-economic position of older people from ethnic minority groups in Britain. Population Trends, 1o1, Autumn, 11-8.

Foster, L. 2013. Gender and pensions: an analysis of factors affecting women's private pension scheme membership in the UK. Journal of Aging and Social Policy, 25, 3, 197-217.

Ginn, J. and Arber, S. 2001. Pension prospects of minority ethnic groups: inequalities by gender and ethnicity. British Journal of Sociology, 52, 3, 519-39.

Gough, O. and Adami, R. 2013. Saving for retirement: a review of ethnic minorities in the UK. Social Policy and Society, 12, 1, 147-61.

Gough, O. and Hick, R. 2009. Ethnic minorities, retirement planning and personal accounts. International Journal of Sociology and Social Policy, 29, 9, 488-97.

Jivraj, S. 2012. How Has Ethnic Diversity Grown I99I-2OOI-2OII? Centre on Dynamics of Ethnicity, Manchester, UK.

Lievesley, N. 2010. The Future Ageing of the Ethnic Minority Population of England and Wales. Runnymede and the Centre for Policy on Ageing, London.

Meyer, T., Bridgen, P. and Andow, C. 2013. Free movement? The impact of legislation, benefit generosity and wages on the pensions of European migrants. Population, Space and Place, 19, 6, 714-26. 
Nesbitt, S. and Neary, D. 2001. Ethnic Minorities and Their Pensions Decisions. Joseph Rowntree Foundation, London.

Office for National Statistics 2005. Focus on Older People. Available online at http:// www.ons.gov.uk/ons/rel/mortality-ageing/focus-on-older-people/2005-edition/ index.html [Accessed 13 January 2014].

Office for National Statistics 2011. Population Estimates by Ethnic Group 2002-2009. Statistical Bulletin. Available online at http://www.ons.gov.uk/ons/taxonomy/ search/index.html?newquery $=* \&$ nscl=Population+Estimates+by+Ethnic+Group\& nscl-orig=Population+Estimates+by+Ethnic + Group\&sortDirection=DESCENDING \&sortBy=pubdate [Accessed 13 January 2014].

Office for National Statistics 201 2. 201 I Census: Key Statistics for England and Wales, March 20 I I. Statistical Bulletin. Available online at http://www.ons.gov.uk/ons/ $\mathrm{rel} /$ census / 201 1-census/key-statistics-for-local-authorities-in-england-and-wales/ stb-201 1-census-key-statistics-for-england-and-wales.html [Accessed 13 January 2014 ].

Office for National Statistics 2013. Aog: Labour Market Status by Ethnic Group. 13 November, Excel spreadsheet $801 \mathrm{~Kb}$. Available online at www.ons.gov.uk [Accessed 6 April 2014].

Office for National Statistics and Department for Work and Pensions 2015. Households Below Average Income. An Analysis of the Income Distribution 1994/95-2013/I4. Office for National Statistics and Department for Work and Pensions, London.

Pensions Policy Institute 2013. The Pensions Primer: A Guide to the UK Pensions System. Pensions Policy Institute, London.

Price, D. 2008. Measuring the poverty of older people. a critical review. Report of an ESRC Public Sector Placement Fellowship, June 2007 to January 2008, King's College London, London.

Sefton, T., Evandrou, M., Falkingham, J. and Vlachantoni, A. 2011 . The relationship between women's work histories and incomes in later life in the UK, US and West Germany. Journal of European Social Policy, 2 1, 1, 20-36.

Steventon, A. and Sanchez, C. 2008. The Under-pensioned: Disabled People and People from Ethnic Minorities. Pensions Policy Institute, London.

van Ginneken, W. 2013. Social protection for migrant workers: national and international policy challenges. European Journal of Social Security, 15, 2, 209-21.

Vlachantoni, A., Feng, Z., Evandrou, M. and Falkingham, J. 2015. Ethnicity and occupational pension membership in the UK. Social Policy E⿱乛⿻ Administration, 49, 7, 801-23.

Wimmer, A. 2008. The making and unmaking of ethnic boundaries: a multilevel process theory. American Journal of Sociology, 113, 4, 970-1022.

Accepted 5 January 20I6; first published online 26 February 2016

Address for correspondence:

Athina Vlachantoni, Centre for Research on Ageing,

Faculty of Social, Human and Mathematical Sciences, University of

Southampton,

Southampton $\mathrm{SO}_{1} 7 \mathrm{BJ}$, UK

E-mail: a.vlachantoni@soton.ac.uk 